\title{
O LETRAMENTO E A ORGANIZAÇÃO DA INFORMAÇÃ̃O DIGITAL ALIADOS AO APRENDIZADO AO LONGO DA VIDA
}

\author{
LITERACY AND THE ORGANIZATION OF DIGITAL INFORMATION COUPLED WITH \\ LIFELONG LEARNING
}

EL LITERACIA Y LA ORGANIZACIÓN DE LA INFORMACIÓN DIGITAL ALIADOS AL APRENDIZAJE A LO LARGO DE LA VIDA

${ }^{1}$ Sonia Boeres

Universidade de Brasília ${ }^{1}$

\author{
Correspondência \\ ${ }^{1}$ Sonia Boeres \\ Universidade de Brasília \\ Brasília, DF - Brasil \\ Email: sonia.boeres@gmail.com \\ ORCID: http://orcid.org/0000-0003-2316-385X
}

Submetido em: 20/01/2018

Aceito em: 15/03/2018

Publicado em: 21/03/2018

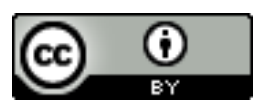

JITA: CE. Literacy. 
RESUMO: O letramento digital é fruto de pensamento crítico e busca potencializar os métodos de estudo pela tecnologia da informação. A questão de pesquisa aqui tratada é compreender como o letramento digital pode contribuir para o aprendizado ao longo da vida. O objetivo é traçar um paralelo entre o letramento e a informação digital e o aprendizado ao longo da vida. Como metodologia fez-se uma revisão de literatura, nacional e internacional, sobre o processo de ensino e aprendizagem, letramento informacional, digital e aprendizado ao longo da vida. Esta pesquisa é de natureza descritiva e base qualitativa. Os principais resultados observados foram que o letramento digital leva a variadas práticas de leitura e escrita por meio das tecnologias da informação. Estas trazem novas possibilidades para educadores e educandos, profissionais e usuários, transcendendo o simples ato de decodificar sinais ou pesquisar na Internet. Ser letrado digitalmente leva à compreensão de que a tecnologia da informação vai além de novas formas de acesso à informação, mas também a novos processos cognitivos e formas de conhecimento. Chegando-se a esse patamar, cabe o árduo e prazeroso trabalho de manter-se atualizado ao longo do tempo, por meio de um esforço pessoal, que envolvem cursos e treinamentos como fonte de aprendizagem e desenvolvimento de trabalho em conjunto com especialistas. Em suma, há que se manter atualizado, acompanhando a evolução tecnológica, e para tanto, ser destemido das tecnologias e do uso das mídias digitais.

PAlaVRAS-ChAVE: Letramento digital. Organização informacional. Competência informacional. Pensamento crítico. Aprendizagem ao longo da vida. Tecnologia da informação.

ABSTRACT: Digital literacy, the subject of study of this article, is the result of critical thinking and seeks to enhance the methods of study by information technology. The research question addressed here is to understand how digital literacy can contribute to lifelong learning. The goal is to draw a parallel between literacy and digital information and lifelong learning. As methodology adopted, a literature review was carried out, both nationally and internationally, on the teaching and learning process, information literacy, digital and lifelong learning. This research is descriptive in nature in a qualitative basis. The main results observed were that digital literacy leads to a variety of reading and writing practices through information technology. These bring new possibilities for educators and learners, professionals and users, transcending the simple act of decoding signals or searching the Internet. Being digitally literate leads to the understanding that information technology goes beyond new forms of access to information, but also to new cognitive processes and forms of knowledge. It is an arduous and pleasurable work to keep up-to-date through time, through a personal effort, involving courses and training as a source of learning and development of work together with specialists. In short, we must search lifelong learning, following the technological evolution, and for that, being fearless of technologies and of the use of digital media.

KEYWORDS: Digital literacy. Information organization. Informational competence. Critical thinking. Lifelong learning. Information Technology.

RESUMEN : El letramento digital, tema de estudio de este artículo, es fruto de lo pensamiento crítico, y busca potenciar los métodos de estudio por la tecnología de la información. La cuestión de la investigación aquí tratada es comprender cómo el letramento digital puede contribuir al aprendizaje a lo largo de la vida. El objetivo es trazar un paralelo entre el letramento y la información digital y el aprendizaje a lo largo de la vida. Como metodología se hizo una revisión de literatura, nacional e internacional, sobre el proceso de enseñanza y aprendizaje, letra de la información, digital y aprendizaje a lo largo de la vida. Esta investigación es de naturaleza descriptiva y base cualitativa. Los principales resultados observados fueron que el letramento digital lleva a variadas prácticas de lectura y escritura a través de las tecnologías de la información. Estas traen nuevas posibilidades para educadores y educandos, profesionales y usuarios, trascendiendo el simple acto de decodificar señales o buscar en Internet. El ser letrado digitalmente lleva a la comprensión de que la tecnología de la información va más allá de nuevas formas de acceso a la información, pero también a nuevos procesos cognitivos y formas de conocimiento. Al llegar a ese nivel, cabe el arduo y placentero trabajo de mantenerse actualizado a lo largo del tiempo, a través de un esfuerzo personal, que involucra cursos y entrenamientos como fuente de aprendizaje y desarrollo de trabajo en conjunto con especialistas. En resumen, hay que mantenerse actualizado, acompañando la evolución tecnológica, y para tanto, ser intrépido de las tecnologías y del uso de los medios digitales

PAlABRAS Clave: Literacia digital. Organización de la informacional. Competencia informacional. Pensamiento crítico. Aprendizaje a lo largo de la vida. Tecnología de la información. 


\section{INTRODUÇÃ̃o}

Alguns autores confundem o conceito de letramento informacional com o de alfabetização informacional. A expressão 'letramento informacional' foi cunhada em 1974, por Paul Zurkovisky, à época presidente da Information Industry Association, tendo usado a expressão para o US National Commission on Libraries and Information Science. Soares (2003, p.32) afirma que a palavra letramento apareceu pela primeira vez no livro de Mary Kato: "No mundo da escrita: uma perspectiva psicolinguística", em 1986. Os estudos internacionais sobre o assunto intensificaram-se principalmente a partir das duas últimas décadas do século passado, mais especificamente em 1990, no National Forum on Information Literacy (NFIL), ficando mais forte a partir de 2004. O termo chegou ao território brasileiro no início deste século XXI. Do original em inglês, Information Literacy, tem sido traduzido no Brasil como 'competência informacional', mas autores como Gasque (2006, 2008), Neves (2008) e Campello (2009) optaram por usar 'letramento informacional'.

Dado o uso de palavras diferentes para designar conceitos semelhantes, faz-se necessário, primeiramente, definir o que é alfabetização informacional. Este termo foi inicialmente considerado por Caregnato, seguindo o uso conceitual da Espanha (GASQUE, 2012, p. 28) é a primeira etapa do letramento informacional. Definida como a decodificação de um indicador em que o indivíduo desenvolve noções a respeito de instrumentos e processos de aprendizagem, enquanto o letramento informacional traz a ideia de funcionalidade e aplicação de processos no cotidiano.

Já competência informacional é a capacidade de o aprendiz mobilizar o próprio conhecimento. É produto da aprendizagem, resultado do saber fazer uso da informação. Ao longo do processo de letramento informacional, os aprendizes desenvolvem competências para identificar a necessidade de informação, avaliar, buscar e usá-la eficaz e eficientemente, considerando os aspectos éticos, legais e econômicos. A competência informacional é um produto do letramento, e propõe-se que ela seja utilizada como demonstração do 'saber fazer', proveniente das relações entre o conhecimento que o sujeito detém, ou seja, a experiência adquirida pela prática e a reflexão sobre a ação (GASQUE, 2003).

Campelo (2009, p. 75) adotou em sua tese a definição de Doyle (1992, p. 4) ressaltando que o "letramento informacional é a habilidade de acessar, avaliar e usar informação de uma variedade de fontes”. Dudziak (2003, p. 30) recomenda três categorias diferenciadas: ênfase na tecnologia da informação (concepção da informação), nos processos cognitivos (concepção cognitiva) ou ainda no aprendizado (concepção da inteligência). Campello (2009), porém, parte da perspectiva de Bruce (1997), ao fazer distinções entre as concepções de letramento informacional, apresentado por sete características: a da TI, as fontes de informação, o processo de informação, o controle da informação, a construção do conhecimento, a extensão do conhecimento e a concepção de inteligência. 
Diferenciados os termos, aqui utilizaremos a definição de letramento informacional como o “... processo que integra as ações de localizar, selecionar, acessar, organizar, usar informação e gerar conhecimento, visando à tomada de decisão e à resolução de problemas" (GASQUE, 2010, p. 83). Portanto, o letramento informacional tem como finalidade a adaptação e a socialização dos indivíduos na sociedade da aprendizagem. Sua essência consiste no engajamento do sujeito no processo de aprendizagem, a fim de desenvolver competências e habilidades necessárias à busca e ao uso da informação, de modo eficaz, fundamentando a tomada de decisão.

Leite e Botelho (2011, p. 13) e Buzato (2012, p. 785) se referem ao termo letramento no plural. Para Leite e Botelho o que há são "letramentos múltiplos", relacionados às variadas práticas de leitura e escrita, que trazem novas possibilidades para educadores e educandos, transcendendo o simples ato de decodificar sinais.

\section{LETRAMENTO DIGITAL: CONCEITO E PERSPECTIVAS}

De acordo com Borges e Silva (2005), as pessoas estão inseridas na Sociedade da Informação quando são capazes de desenvolver as habilidades necessárias para acessar e usar a informação. Com o advento da Internet, a sociedade, a economia e a cultura veem suas fronteiras mudarem, uma vez que "a virtualização da realidade arquiteta novos espaços e tempos a velocidades inusitadas" (GASQUE; TESCAROLO, 2010, p. 42).

Este trabalho se justifica na escassa literatura sobre letramento digital, no Brasil. Em artigo, Rocha et all (2008, p. 147) concluíram que o letramento informacional era pouco abordado pelos autores. Eles fizeram um levantamento em 13 periódicos nacionais nas áreas de Biblioteconomia e Ciência da Informação, entre 2004 e 2008, que tratavam do assunto, e avaliaram que do total de revistas analisadas em 5 anos, apenas $67 \%$ tratavam do assunto. Letramento digital é um tema ainda mais novo, contando com uma limitada literatura nos artigos brasileiros.

Essa pesquisa é fruto de parte da revisão de literatura, nacional e internacional, sobre o processo de ensino e aprendizagem, letramento informacional, digital e aprendizado ao longo da vida, utilizada em nossa tese. Esta pesquisa é de natureza descritiva e base qualitativa, tendo como objetivo traçar um paralelo entre o letramento e informação digital e o aprendizado ao longo da vida. O problema que norteia este artigo consiste em compreender como o letramento digital pode contribuir para o aprendizado ao longo da vida.

Na aprendizagem por meio de Tecnologia da Informação (TI), Soares (2002) discute as práticas de leitura e escrita na cibercultura, e enfatiza a ideia de que "diferentes espaços de escrita e diferentes mecanismos de produção, reprodução e difusão da escrita resultam em 
diferentes letramentos" (p. 156), reconhecendo a existência de diversos processos de letramento.

Belluzzo (2005, p. 1) enfatiza a importância da educação, sob o enfoque de um novo paradigma conceitual e prático, voltado para a formação de cidadãos capazes de se integrarem à era digital, cujo princípio fundamental acha-se no desenvolvimento de competências para o uso da informação, bem como a capacidade intelectual de transformá-la em conhecimento, com uma inovadora condição de aprendizado contínuo e crescente. Tudo isso frente aos desafiadores avanços técnico-científicos dos últimos tempos. Esta autora (p. 15) afirma que a competência em informação apresenta diferentes concepções que podem ser resumidas em:

- digital - concepção com ênfase na tecnologia da informação e da comunicação;

- informação propriamente dita - concepção com ênfase nos processos cognitivos;

- social - concepção com ênfase na inclusão social, consistindo em uma visão integrada de aprendizagem ao longo da vida e exercício de cidadania.

Vê-se, então, que o letramento digital envolve não apenas o uso da informação e das tecnologias, mas o

acompanhar consciente e deliberadamente uma mudança de civilização que questiona profundamente as formas institucionais, as mentalidades e a cultura dos sistemas educacionais tradicionais e sobretudo os papéis de professor e de aluno, o que requer uma profunda mutação na relação com o saber (LÉVY, 1999, p.172).

Em concordância com o exposto, trazendo a discussão para o âmbito da Ciência da Informação, vê-se que esta ciência deveria se focar em elementos de três mundos:

(1) o mundo da realidade subjetiva, como espaço do arcabouço e das construções teóricas, dos conteúdos de significação conceitual relacionados à geração, interpretação e assimilação da informação como mediadora do conhecimento; (2) o mundo da realidade dos objetos e técnicas, como espaço dos sistemas materiais de acervamento de documentos, dos instrumentos, das normas e técnicas relativas ao controle dessa agregação, desse armazenamento e da recuperação da informação para possível uso; e (3) o mundo da realidade do ciberespaço, como espaço dos símbolos cibernéticos, lugar dos estoques eletrônicos dos documentos em formato digital, das redes de colaboração em tempo real, ou seja, o lugar das interfaces e comunicação entre os humanos e o computador, um espaço onde se pode habitar por vivência, mas sem presença (BARRETO, 2009, p. 11).

A educação passa a ter uma outra individualidade, a de transmissora de informação e de cultura, para ensinar a aprender e a pensar, ligando os conhecimentos adquiridos para empregar esta inteligência na vida profissional e no seu cotidiano. Um novo paradigma surge na formação de cidadãos capazes de associarem-se à era digital, cujo princípio é o desenvolvimento de competências para usar informação, e capacidade intelectual de transformá-la em conhecimento no contexto de um aprendizado contínuo e crescente. No mundo digital, a atuação da biblioteca é fundamental na busca e alcance da qualidade na educação, dadas as novas exigências da sociedade (BELLUZZO, 2005, p. 9).

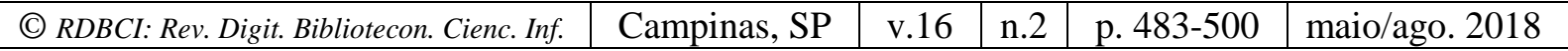


Em tempos digitais um dos objetivos da educação é prover e facilitar o acesso à informação acoplada à Internet, com avaliação dos conteúdos, conhecimentos das tecnologias envolvidas, além do uso adequado da informação acessada (ROBREDO, 1989). Na mudança do físico para o virtual é necessário refletir sobre as competências que se deve desenvolver em educadores, bibliotecários e estudantes.

Para Mey (1998), a relevância do letramento, tanto do informacional quanto do digital, vai além de se assegurar que é uma tecnologia de informação. É saber utilizar esses recursos para aplicá-los no cotidiano, em benefício do próprio usuário. É necessário averiguar o porquê de se fazer uma busca na web, e saber qual a finalidade dessa informação para a vida, de modo a promover a aquisição de um (novo) conhecimento.

Soares (2002) tem a visão de que letramento digital confronta tecnologias digitais de leitura e de escrita com tecnologias tipográficas, e adverte que cada uma tem seu espaço e um efeito na sociedade, resultando em conceitos diferentes de letramento. Ela observa que o letramento digital é usado para aludir à prática de leitura e escrita possibilitada pelo computador e pela Internet. Segue apresentando uma nova visão no conceito de letramento e a confrontação de tecnologias digitais de leitura e de escrita, com tecnologias tipográficas, salientando que cada uma tem seu espaço e um efeito na sociedade, resultando em conceitos diferentes de letramento.

O conceito de letramento digital surgiu em 1997 com Paul Gilster, em seu livro com o mesmo título (Digital literacy, em inglês). Antes dele, na década de 90, outros autores usavam o termo como uma habilidade de ler e compreender itens informacionais em hipertexto, ou em formatos digitais, que estavam se popularizando naquela década. Para Gilster (1997) letramento digital é a habilidade de entender e usar informação em uma variedade de fontes digitais.

De acordo com Ribeiro (2009, p. 4), o conceito de letramento digital é complexo e amplo, já que uma pessoa pode ser letrada (ter habilidade) somente para usar a Internet, acessando e-mails ou conversando em redes sociais, por exemplo. Ainda assim ele crê que as pessoas precisam aprender a fazer uso da tecnologia para gerar um benefício ou comodidade para elas, como ao procurar emprego pela Internet, o que implica nos passos de ler o anúncio, interpretar e candidatar-se à vaga via TI.

Xavier (1999, p. 1) considera a necessidade de os indivíduos dominarem um conjunto de informações e habilidades mentais que devem ser trabalhadas com urgência pelas instituições de ensino, a fim de rapidamente capacitar os alunos para assumirem sua cidadania nos novos tempos, estando eles cada vez mais cercados por máquinas eletrônicas e digitais. Gilster (2006 apud BAWDEN, 2008) diz que a pessoa letrada digitalmente é capaz de usar e entender informações vindas de vários suportes digitais. Neste sentido, o letrado 
digital tem a habilidade de usar essa nova tecnologia a fim de proporcionar uma melhoria em sua qualidade de vida.

Souza (2007, p. 57) nos mostra a complexidade de se definir letramento digital a começar, segundo ela, pela falta de um termo academicamente validado, uma vez que se encontram variações como "letramento eletrônico, letramento tecnológico, competência tecnológica, dentre outros". A mesma autora complementa dizendo que "letramentos digitais constituem formas diversas de prática social que emergem, evoluem, transformam-se em novas práticas e, em alguns casos, desaparecem, substituídas por outras" (SOUZA, 2007, p. 59, 60). Ela entende:

[...] letramento digital como o conjunto de competências necessárias para que um indivíduo entenda e use a informação de maneira crítica e estratégica, em formatos múltiplos, vinda de variadas fontes e apresentada por meio do computador, de maneira crítica e estratégica, sendo capaz de atingir seus objetivos, muitas vezes compartilhados social e culturalmente.

Já para Buzato (2006, p. 9):

Letramentos digitais (LDs) são conjuntos de letramentos (práticas sociais) que se apoiam, entrelaçam, e apropriam mútua e continuamente por meio de dispositivos digitais para finalidades específicas, tanto em contextos socioculturais geográfica e temporalmente limitados, quanto naqueles construídos pela interação mediada eletronicamente.

Gasque e Azevedo (2012, p. 3) apontam o vínculo às inovações tecnológicas, de modo a compreender que o letramento digital acompanha a evolução dos contextos tecnológico, econômico, social, cultural e político de uma dada sociedade, exigindo o domínio da língua escrita. Implica em conhecer a geração digital, cada vez mais apta às mudanças ocasionadas pelas novas tecnologias da informação e comunicação.

No livro A hora da geração digital, Tapscott (2010) a apresenta ao contextualizar como a Internet chega à maturidade, possibilitando uma geração imersa em bits. Aponta oito 'normas da geração Internet', ao mostrar como funciona o cérebro dessa geração: liberdade, personalização, escrutínio, integridade, colaboração, entretenimento, velocidade e inovação:

Esses jovens valorizam a liberdade - liberdade para ser quem quiserem, liberdade de escolha. Querem customizar tudo, até mesmo o próprio emprego. Aprendem a ser céticos, a analisar o que veem e leem na mídia, inclusive na internet. Dão valor à integridade - ser honesto, respeitoso, transparente e cumpridor dos compromissos. São ótimos colaboradores, com amigos on-line e no trabalho. Vivem em alta velocidade. Adoram inovar. Essa é a Geração Internet (TAPSCOTT, 2010, p. 118 119).

Em 2010 o pensamento fazia mais sentido, oito anos depois, porém, vê-se que a integridade, honestidade e respeito de parte desta geração virtual está sob questionamento em nível social. Escondidos por trás da tela alguns se sentem mais à vontade para desrespeitarem

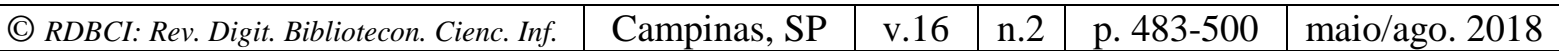


o outro do que talvez o fizessem cara a cara, e a transparência tem sido levada para situações de exposição indevida da vida particular.

Prensky (2011, p. 1), após escrever um artigo intitulado Nativos e Imigrantes Digitais conceituou a geração tecnológica como nativos digitais, sendo aqueles que cresceram cercados por tecnologias digitais. Compara a geração atual e as gerações anteriores. Para a primeira, a tecnologia analógica, câmeras de vídeo, telefones com fio, informação não conectada (livros) e Internet discada são coisas ultrapassadas, velhas. São nativos digitais aqueles que cresceram com a tecnologia digital e a usaram sem medo, pois a veem como um aliado. Diferente da geração anterior, denominada por ele como imigrantes digitais, aqueles que precisam se adaptar à tecnologia digital. Pouco depois, a distinção entre os termos nativo e imigrante digital saiu de foco, dada a visibilidade do século XXI ser caracterizada pela era da tecnologia digital. Pode-se afirmar que o digital é o fenômeno da contemporaneidade, ocasionando significativas mudanças no âmbito profissional, educacional, familiar e social.

Portanto, o letramento digital tende a levar ao desenvolvimento de competências indispensáveis ao "manuseio" de ferramentas que contribuem para a leitura e escrita utilizando a tecnologia digital. Inúmeros autores abordam o tema das tecnologias, com múltiplos conceitos voltados ao letramento digital, possibilitando cada vez mais a amplitude da literatura, e também embasando, de certa forma, a relevância de ser um letrado digital, conforme apresentaremos a seguir. Ressalte-se que para o pleno desenvolvimento do letramento digital é imperativo que a informação esteja organizada, acessível, e que seu usuário esteja atualizado o suficiente para saber encontrá-la e utilizá-la.

\section{PORQUE SER LETRADO DIGITAL?}

Lanhan, Tuman e Landow (apud XAVIER, 1999) acreditam que o hipertexto e a Internet possibilitam a integração entre as várias disciplinas, dissipando os limites entre as áreas do conhecimento. Segundo eles, o usuário do hipertexto tende a processar com mais velocidade a leitura, e a desenvolver o pensamento 'criativo', aperfeiçoando a capacidade de análise e cruzamento de informações. É necessário lembrar que o uso de algum tipo de letramento em uma sociedade não é igualmente universal, já que ele está relacionado às condições de desigualdades socioeconômicas e históricas, vividas ao redor do globo.

Para Xavier (1999, p. 3) esta nova forma de aprendizagem, o letramento digital, se diferenciaria por ser mais dinâmica, participativa, tirando o centro da figura do professor e arrolando-a à independência, autonomia, necessidades e interesses imediatos de cada um dos aprendizes, que são usuários frequentes das tecnologias de comunicação digital. O letramento digital demanda que o indivíduo assuma enfoques pedagógicos que vão além dos limites físicos das instituições de ensino. 
Soares (2002, p. 152) ainda nos lembra que a tela é um espaço de escrita e de leitura que traz não apenas novas formas de acesso à informação, mas novos processos cognitivos, formas de conhecimento e maneiras de ler e de escrever. Ou seja, um novo letramento, no sentido de ser uma nova condição para aqueles que leem e escrevem na tela. E, segundo Porto (2006), para abordar as possibilidades do uso de tecnologias na educação deve-se considerar o pressuposto de que deve haver uma preparação docente. Ela ainda nos lembra do potencial educativo da TI, como a rapidez, recepção individualizada, interatividade e participação, hipertextualidade, realidade virtual e digitalização. Indo além, cremos que o letramento digital e o uso das TI precisam agregar valor às atividades que os alunos ou os professores realizam, ou seria "apenas" uma mudança na plataforma educacional.

De acordo com Moreira (2012, p. 4) a necessidade de um indivíduo ser letrado digitalmente surgiu a partir da ideia de que "uma fonte digital pode gerar muitas formas de informações de texto, como imagens, sons, etc. Por isso, uma nova forma de alfabetização era necessária com o intuito de dar sentido a essas novas formas de apresentação".

Os usuários de Internet cumprem ao mesmo tempo a função de leitores e autores, escolhendo as informações que querem ler, ou com quais querem contribuir, por exemplo, via folksonomia, onde o 'povo' (indivíduo) indexa conteúdo na web. Cosette Castro (2012, p.25), levanta a questão das mudanças tecnológicas decorrentes da transformação do mundo analógico para o digital, e diz que elas implicam na necessidade de novos paradigmas, "é a passagem da comunicação unidirecional (produção - mensagem - recepção) para a comunicação bidirecional, dialógica e interativa". A aprendizagem passa, então, a ser vista pela corrente socioconstrutivista como mais duradoura e eficaz, permitindo que o aluno absorva "o como fazer" motivado por uma situação prática de necessidade, sem exercícios mecânicos pré-construídos para este fim.

Termos como letramento na web (web literacy), letramento informacional crítico (critical information literacy), letramento digital crítico (critical digital literacy), metaletramento (metaliteracy) e pedagogia híbrida (hibrid pedagogy) têm emergido na literatura. Mercurio e Bernstein (2018), citando Kris Shaffer, dizem que competências ligadas a tais assuntos se mostram como mais do que o letramento tradicional, carecendo de trazer professores e alunos para desenvolverem um entendimento mais sofisticado de como a informação é produzida, consumida e disseminada online, especialmente com respeito às implicações tecnológicas, sociológicas e psicológicas das mídias digitais conectivas. Os profissionais de informação devem refletir sobre como revisar seus próprios objetivos de aprendizagem. Mudanças curriculares podem ser necessárias de modo a ajudar profissionais e, consequentemente, os usuários dos centros de informação, no desenvolvimento de habilidades e parcerias necessárias para implementar a aproximação com o letramento digital. 


\section{SE É BOM, POR QUE NÃO?}

Surge um desafio: apesar de vivermos numa era digital, incentivar os professores a ministrar uma aula mediada pela tecnologia continua não seja tão fácil ou simples, muitos ainda têm a concepção da aprendizagem centrada no educador. Há que se agregar competências tecnológicas que alterem o sistema educacional e a formação dos professores. Também deve-se analisar seus impactos sobre a valorização da informação e do conhecimento como bens de valor (MOREIRA, 2012, p. 1). Para ela, os Parâmetros Curriculares Nacionais - brasileiros - (PCNs) incentivam o uso das novas tecnologias, em conjunto com as disciplinas, porém ainda se tem a resistência (ou desatualização que gera desconhecimento?) do professor na utilização da tecnologia, de forma útil e consciente, na sala de aula. Cada docente tem uma cultura diferente, ocasionando formas de pensar diferentes em relação ao uso do computador como ferramenta pedagógica. Para alguns professores o não usar as tecnologias de informação tem a ver com a pouca infraestrutura definida nas escolas, algumas vezes não contando com um profissional da área de TI para auxiliá-los.

O uso das ferramentas computacionais (computadores, Internet e outros) pode ser feito durante as aulas, facilitando o trabalho do professor e ajudando na compreensão, por parte dos alunos. Porém, desde Xavier (1999, p. 2) se verificava uma forte rejeição a um novo modo de ensinar, ainda mais quando os alunos começam a buscar outras fontes de informação, além do professor e do livro didático. Siqueira (2004, p. 194) ressalta que "a grande qualidade da Internet é a interatividade, que possibilita, em educação, o uso de métodos mais dinâmicos e avançados de aprendizagem". Assim, é necessário investir nesse profissional desde a sua formação inicial até a continuada (aprendizagem ao longo do tempo), para que ele possa colaborar mais para a aprendizagem, trazendo as novas tecnologias digitais para seu modo de ensinar, integrando-as às técnicas que habitualmente utiliza.

Como bem concluiu Moreira (2012), não basta trazer o computador para a sala e ministrar uma aula mais interativa. É importante transmitir o conteúdo de forma clara, sem deixar que o brilho da tecnologia apague a figura do professor. Como já dito, o acesso à TI não assegura o domínio de suas ferramentas ou certifica a compreensão dos recursos oferecidos e não é o caso de substituir o professor pelas máquinas. A competência do primeiro deve incentivar a aprendizagem e o pensamento crítico dos alunos. A atividade dos professores se concentrará no acompanhamento das aprendizagens, instigando a "troca dos saberes, a mediação relacional e simbólica, a pilotagem personalizada dos percursos de aprendizagem" (LÉVY, 1999, p. 171). Para ele "O professor torna-se um animador da inteligência coletiva dos grupos que estão a seu encargo". 
Há uma geração de profissionais que começou, e continua, levando sua vida profissional distante do mundo digital, por 'medo' da TI ou desconhecimento de como utiliza-la, e isso tem se mostrado um entrave ao desenvolvimento do letramento digital.

\section{APRENDIZADO AO LONGO DA VIDA}

Sobre letramento digital Beluzzo (2001) levantou três componentes:

- $\quad$ aprendizado ativo para impacto no desempenho;

- $\quad$ aprendizado continuo, ao longo da vida;

- $\quad$ pensamento crítico.

Atualmente se requer a aprendizagem de competências específicas que se organizam no processo do letramento informacional, alicerce para a gestão da informação, fundamentada na aprendizagem permanente, que deverá ocorrer ao longo de toda a vida das pessoas, abrangendo todas as disciplinas, ambientes de aprendizagem e níveis de ensino (ACRL, 2000).

Também para Dudziack (2003, p. 28 apud ROCHA, 2008), o processo do letramento informacional envolve o aprendizado de longo prazo "processo contínuo de internalização de fundamentos conceituais, atitudinais e de habilidades necessárias (...) de modo a proporcionar um aprendizado ao longo da vida".

Uma questão que surge quanto ao aprendizado ao longo da vida é: de onde ele vem? Como alcança-lo? Na tese de Gama (2013), ela levanta três maneiras de obtê-lo, que seria por meio:

1. do esforço pessoal;

2. do trabalho, ou com especialistas;

3. de cursos e treinamentos.

$\mathrm{Na}$ análise dos dados de seu estudo (GAMA 2013, p. 439) ela conclui que, quanto à origem do aprendizado: "23\% indicaram os cursos e treinamentos como a fonte da aprendizagem, $31 \%$ identificaram que este conhecimento deriva de esforço pessoal, $23 \%$ disseram que aprenderam no trabalho ou com especialistas...". Mais adiante (GAMA 2013, p. 441), questionados sobre saber como usar serviços especializados on-line e saber manipular textos digitais, imagens e transferência de dados dos formatos originais para um novo contexto, novamente os respondentes disseram que primeiramente dependem do esforço pessoal (37\%), mas as duas respostas obtidas, em segundo e terceiro lugar, se diferenciaram das acima, e eles disseram não dispensar a necessidade de cursos ou treinamentos (27\%) e da aprendizagem que ocorre no trabalho ou com especialistas (23\%). Assim, conclui-se que o esforço pessoal é a mola propulsora do aprendizado ao longo da vida, não dispensando a interação com colegas e especialistas, e a participação em cursos e treinamentos. 
A premissa do esforço pessoal está em concordância com a teoria do letramento, por meio da tese de um de seus fundamentadores, John Dewey, que tem no pensamento reflexivo a parte da "ação", a prática da aprendizagem, que também se relaciona com outra de suas teorias, a da experiência, contada não apenas em anos de vida, mas principalmente no aprender, que não é só memorizar, mas vivenciar o conhecimento. O aprendizado ao longo da vida interage com a prática profissional e a reflexão sobre a ação do aprender. É aprender a pensar, levando-se em conta as experiências e informações adquiridas no viver, que abrangem as atitudes, as disposições morais e o cultivo das apreciações estéticas. É o conjunto das mudanças permanentes advindas das relações entre a nova informação, a reflexão e a experiência prévia, sem desconsiderar as interações do indivíduo com o meio social (DEWEY, 1979). Em suma, não há como se discutir letramento informacional e digital e os conceitos a ele relacionados, sem se referir ao processo de aprendizagem de longo prazo.

De acordo com Behrens (2000, p.67), "a humanidade tem sido desafiada a testemunhar duas transições importantes que afetam profundamente a sociedade: o advento da sociedade do conhecimento e a globalização". O mundo vive, segundo a autora, um processo de mudança paradigmática que atinge todas as instituições, em especial a educação e o ensino nos diversos níveis, inclusive e principalmente nas universidades. Considerando essas transformações, impulsionadas pelas novas tecnologias da informação e comunicação, "as pessoas precisam estar preparadas para aprender ao longo da vida, podendo intervir, adaptar-se e criar novos cenários” (BEHRENS, 2000, p. 68).

Ser letrado digitalmente na sociedade da aprendizagem implica saber lidar com a complexidade que envolve a informação, cada vez mais gerada de forma ilimitada. As pessoas não precisam mais ficar estáticas diante de um computador, uma vez que os aplicativos móveis possibilitam a conexão o tempo todo. Neste sentido, aprender ao longo da vida consiste em aprender a aprender o tempo todo, considerando a evolução das tecnologias da informação e comunicação, apropriando-se delas o quanto possível. Um letrado digital é um ser capaz de acompanhar as informações nos mais diversos espaços virtuais, aprendendo a partir das mudanças, dominando os recursos disponíveis à informação:

\footnotetext{
Entre todas as tecnologias criadas pelos seres humanos, aquelas relacionadas com a capacidade de representar e transmitir informação - ou seja, as tecnologias da informação e comunicação - revestem-se de uma especial importância, porque afetam praticamente todos os âmbitos de atividade das pessoas, desde as formas e práticas de organização social até o modo de compreender o mundo, de organizar essa compreensão e de transmiti-la para outras pessoas (COLL, MONEREO, 2010, p. 17).
}

A aprendizagem ao longo da vida é um conceito que complementa a teoria do letramento, em tempos de grande volume de informação como o que se vive. Segundo a UNESCO (ABID, 2004) a capacidade de lidar com a informação torna-se um pré-requisito do saber, e o desenvolvimento dessa competência é fator determinante para a integração das pessoas no mundo do trabalho, no social e no cultural. 
O tema também é conexo com a teoria do pensamento reflexivo de Dewey, que é aquele senso crítico a ser despertado no ser humano, de modo a possibilitar a construção das competências necessárias à busca e ao uso da informação. Gasque e Cunha (2010) ressaltam a contribuição de Dewey à educação, ao direcionarem o conhecimento ao desenvolvimento pessoal e coletivo, ocasionando a perspectiva de um saber ético, inteiramente comprometido com a sociedade: "A filosofia "Deweyana" compreende a pessoa livre para escolher as ações e tomar decisões em um processo social, democrático, de supostas oportunidades iguais para todos" (GASQUE, CUNHA, 2010, p.140).

Nas conclusões de sua pesquisa, Gama (2013) afirma que a competência informacional é resultado da aprendizagem ao longo da vida de modo cumulativo, ou seja, cada novo conhecimento se soma ao anterior, preparando o indivíduo para a solução de problemas de maior complexidade. A autora sintetiza que são a automotivação e a autodeterminação as grandes responsáveis pela aprendizagem advinda da aprendizagem continuada.

Para Grose (2014), a tecnologia dá apoio à abordagem construtivista, e as práticas de ensino apoiadas por tecnologias digitais ativam o tipo de aprendizado defendido pelas ciências da aprendizagem, que exigem mudanças significativas em questões pedagógicas. $\mathrm{O}$ uso de tecnologias com alunos somente é bem-sucedido quando efetivamente usado como uma ferramenta para apoiar práticas pedagógicas, e estas estão ligadas ao ensino e aprendizagem autênticos.

A aprendizagem ao longo da vida está se tornando um imperativo também econômico, a mudança tecnológica exige conexões mais fortes e contínuas entre educação e emprego. Uma pesquisa apontou que 54\% dos americanos que trabalham acham que será essencial desenvolver novas habilidades ao longo de suas vidas, entre os adultos com menos de 30 anos, o número vai até $61 \%$. Outra pesquisa mostrou que $93 \%$ estavam dispostos a gastar seu próprio dinheiro em treinamento adicional, dada a importância que viam em manterem-se atualizados (THE ECONOMIST, 2017).

Em estudo com profissionais de outra área, que não a Ciência da Informação, a respeito de aprendizado ao longo do tempo, Schwartz et all (2018) notaram que os profissionais do milênio desfrutam de aprendizado colaborativo, funcionam bem em grupos, são tecnicamente inteligentes, apreciam expectativas claras e esperam feedbacks frequentes e individualizados sobre seu desempenho. Segundo os autores, os educadores devem determinar o que funciona melhor para cada indivíduo, criar uma cultura de verificação e, o mais importante, alimentar este espírito de aprendizagem ao longo da vida.

Em suma, a educação continuada é um tema importante, com implicações extraordinárias para os profissionais da informação, em especial os bibliotecários que, cada vez mais, trabalham em bibliotecas mutantes (físicas e virtuais) e de cultura rotacionada pela cultura digital. 


\section{CONSIDERAÇÕES FINAIS}

No mundo digital com informações organizadas, a mensagem é enviada e logo recebida pelos sujeitos sociais, que têm a possibilidade de responder e interagir em tempo real, transformando radicalmente a relação entre os dois âmbitos, utilizando diferentes plataformas tecnológicas. O letramento digital serve para fazer os indivíduos mais produtivos economicamente, e atende aos que postulam o desenvolvimento da capacidade analítica e crítica do cidadão como objetivo maior da aquisição de qualquer tipo de letramento. Com tantos saberes disponíveis em meio digital, uma questão que não pode ser esquecida é a da preocupação com a preservação de todo este conteúdo em meio digital. Esquecer-se disto é colocar em risco de perda todo este conteúdo explosivamente colocado à disposição, a cada minuto, nas bases de dados digitais.

Os diferentes modos de aprendizagem na sociedade do conhecimento são um desafio a ser reconhecido nos mais diversos espaços educacionais, principalmente nas universidades, ainda caracterizadas pelo tradicional modelo de ensino, com aulas expositivas, sem diversificada interação entre o estudante e o professor. Contudo, é necessário, na amplitude de informações, reconhecer a relevância do letramento informacional, bem como do letramento digital, adequados a capacitar o indivíduo a construir um conhecimento sólido, sistemático, pertinente, inovador e, sobretudo, ao longo do tempo. Da mesma maneira que a informação está sendo divulgada ferozmente, a atualização profissional deve seguir seu exemplo, acompanhando a evolução tecnológica e sem medo ou preconceito com a tecnologia.

\section{REFERÊNCIAS}

ABID, Adbelaziz. UNESCO: information literacy for lifelong learning. Paris: Information Society Division. UNESCO, 2004.

\section{ASSOCIATION OF COLLEGE AND RESEARCH LIBRARY (EUA). Information literacy competency for higher education. Chicago: ALA, 2000.}

AZEVEDO, Isabel Cristina Michelan de; GASQUE, Kelley Cristine Gonçalves Dias. Contribuições do letramento digital e informacional na emancipação humana. Disponível em: <http://maristaonline.org.br/literacia/wpcontent/uploads/2012/06/Contribuicoes-do-letramento-digital-e-informacional_IsabelAzevedo-e-Kelley-Gasque.pdf >. Acesso em 19 abr. 2014.

BAWDEN, David. Origins and concepts of digital literacy. New York: Peter Lang, 2008. p. 17-32.

BARRETO, Aldo. Mediações digitais. DataGramaZero - Revista de Ciência da Informação, v.10, n.4, ago. 2009. Disponível em: <http://www.brapci.inf.br/index.php/article/download/34503>. Acesso em 20 mar. 2018. 
BEHRENS, Marilda Aparecida. Projetos de aprendizagem colaborativa num paradigma emergente. In: MORAN; MASETTO; BEHRENS. Novas tecnologias e mediação pedagógica. Campinas, SP. Papirus, 2000.

BELLUZZO, Regina Célia Baptista. Competências na era digital: desafios tangíveis para bibliotecários e educadores. ETD - Educação Temática Digital, Campinas, v. 6, n. 2, p. 27 42, 2005. Disponível em: 〈file:///D:/Download/772-827-1-PB.pdf >. Acesso em 2 mar 2018.

BELLUZZO, Regina Célia Baptista. A information literacy como competência necessária à fluência científica e tecnológica na Sociedade da Informação: uma questão de educação. In: SIMPÓSIO DE ENGENHARIA DE PRODUÇÃO DA UNESP, 7., 2001, Bauru. Anais eletrônicos... Bauru: UNESP, 2001. Disponível em: < http://www.simpep.feb.unesp.br/ anais8/ana8c.html\#GI >. Acesso em: 12 mar. 2012.

BORGES, Jussara; SILVA, Helena Pereira da. Informação e Mudança: estudo da efetividade dos programas de inclusão digital em Salvador-Bahia. In: CONGRESSO BRASILEIRO DE CIÊNCIAS DA COMUNICAÇÃO, 28. 2005. Rio de Janeiro. Anais... São Paulo: Intercom, 2005. p. 1-15.

BRUCE, Christine. The seven faces of information literacy. Adelaide: Auslib, 1997. 203p.

CAMPELLO, Bernadete Santos. Letramento Informacional no Brasil: práticas educativas de bibliotecários em escolas de ensino básico. 2009. 208 f. Tese (Doutorado em Biblioteca Escolar) - Escola de Ciência da Informação, Universidade Federal de Minas Gerais, Belo Horizonte, 2009. Disponível em: <http://gebe.eci.ufmg.br/downloads/tese\%20campello\%202009.pdf >. Acesso em 4 abr. de 2017.

CASTRO, Cosette. Campo público de televisão digital terrestre no Brasil - dificuldades e avanços. In: Intercom - Sociedade Brasileira de Estudos Interdisciplinares da Comunicação, XXXV Congresso Brasileiro de Ciências da Comunicação, Fortaleza, CE, 3 a 7 set. 2012. Disponível em: < http://www.intercom.org.br/sis/2012/resumos/R7-2500-2.pdf >. Acesso em 3 dez. 2017.

COLL, Monereo. Psicologia da educação virtual: aprender e ensinar com as tecnologias da informação e da comunicação. Porto Alegre: Artimet, 2010.

DEWEY, John. Como pensamos: como se relaciona o pensamento reflexivo com o processo educativo, uma reexposição. 4.ed. São Paulo: Nacional, 1979.

DOYLE, Christina. Outcome measures for information literacy within the national education goals of 1990: final report of the National Forum on Information Literacy. Summary of findings. Washington, DC: US Department of Education, 1992. [ERIC document no; ED 351033]. Disponível em:<http://www.ed.gov/databases/ERIC_Digests/ed372756.html>. Acesso em: 9 nov 2013.

DUDZIAK, Elisabeth Adriana. Information literacy: princípios, filosofia e prática. Ciência da Informação, Brasília, v. 32, n. 1, p. 23-35, abr. 2003. Disponível em:< 
http://www.scielo.br/scielo.php?pid=S0100-

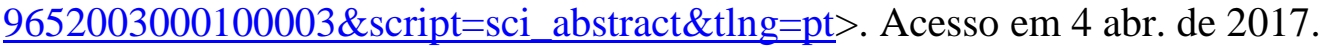

GAMA, Ana Claudia Soares Cavalcante. Competência informacional: aprendizado individual ao longo da vida. 2013. 509 f., il. Tese (Doutorado em Ciência da Informação) Universidade de Brasília, Brasília, 2013. Disponível em:<

http://repositorio.unb.br/handle/10482/12888?mode=full $>$. Acesso em 23 set. 2017.

GASQUE, Kelley Cristine Gonçalves Dias. Arcabouço conceitual do letramento informacional. Ciência da Informação, Brasília, DF, v. 39 n. 3, p.83-92, set./dez., 2010. Disponível em: < http://www.brapci.inf.br/_repositorio/2011/09/pdf_2670248ded_0018745.pdf $>$. Acesso em 8 abr. 2017.

GASQUE, Kelley Cristine Gonçalves Dias. O papel da experiência na aprendizagem: perspectivas na busca e no uso da informação. TransInformação, Campinas, v. 20, n. 2, p. 149-158, maio/ago., 2008. Disponível em: < http://www.scielo.br/scielo.php?pid=S0103-

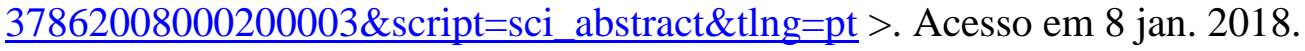

GASQUE, Kelley Cristine Gonçalves Dias; CUNHA, Marcus Vinícius da. A epistemologia de John Dewey e o letramento informacional. TransInformação, Campinas, v. 22, n. 2, p. 139-146, maio/ago., 2010. Disponível em: < http://repositorio.unb.br/handle/10482/9207 >. Acesso em 8 jan. 2018.

GASQUE, Kelley Cristine Gonçalves Dias. Letramento informacional: pesquisa, reflexão e aprendizagem. Brasília: Universidade de Brasília, Faculdade de Ciência da Informação, 2012. 183 p. Disponível em:

$<$ http://leunb.bce.unb.br/bitstream/handle/123456789/22/Letramento_Informacional.pdf?sequ ence=3>. Acesso em 1 abr. 2017.

GASQUE, Kelley Cristine Gonçalves Dias; TESCAROLO, Ricardo. Desafios para implementar o letramento informacional na educação básica. Educação em Revista. Belo Horizonte, v.26, n.01, p. 41-56, abr. 2010. Disponível em: <

http://www.scielo.br/scielo.php?pid=S0102-

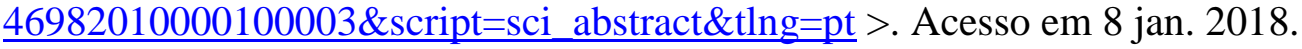

GASQUE, Kelley Cristine Gonçalves Dias. Comportamento dos professores da educação básica na busca de informação para formação continuada. 2003. Dissertação (Mestrado em Ciência da Informação) - Departamento de Ciência da Informação, Faculdade de Estudos Sociais Aplicados, Universidade de Brasília, Brasília. Disponível em: < http://www.repositorio.unb.br/bitstream/10482/636/1/ARTIGO_ComportamentoProfessoresE duca\%C3\%A7\%C3\%A3oB\%C3\%A1sica.pdf >. Acesso em 8 jan. 2018.

GILSTER, Paul. Digital literacy. New York: Wiley Computer Publications, 1997.

GROSE, Karen. From 21st Century Learning to Learning in the 21st Century: Influences on Transforming Teacher Knowledge of Constructivist Practices in Technology-Rich Learning Environments. University of Toronto (Canada), ProQuest Dissertations Publishing, 2014.

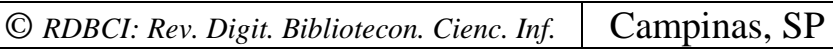

\begin{tabular}{l|l|l|l|} 
v.16 & n.2 & p. $483-500$ & maio/ago. 2018 \\
\hline
\end{tabular}


LEARNING AND EARNING: lifelong learning is becoming an economic imperative. The Economist, Londres, jan. 12, s.n. 2017. Disponível em: <

https://www.economist.com/news/special-report/21714169-technological-change-demandsstronger-and-more-continuous-connections-between-education >. Acesso em 20 mar 2018.

LEITE, Josieli Almeida de Oliveira; BOTELHO, Laura Silveira. Letramentos múltiplos: uma nova perspectiva sobre as práticas sociais de leitura e de escrita. Revista Eletrônica da

Faculdade Metodista Granbery. Juiz de Fora, jan/jun 2011, n. 10, ISSN 19810377.

Disponível em: <http://re.granbery.edu.br/artigos/NDMx >. Acesso em 7 de nov. de 2017.

LEVY, Pierre. Cibercultura. São Paulo, Ed.34, 1999.

MERCURIO, Jeremiah; BERNSTEIN, Matt. Beyond information: new literacies for instruction librarians. In: Georgia International Conference on Information Literacy, Savannah, n. 46, 2017. Disponível em:

<https://digitalcommons.georgiasouthern.edu/gaintlit/2017/2017/46 >. Acesso em: 20 mar. 2018 .

MEY, Jacob L. As vozes da sociedade: letramento, consciência e poder. Tradução de Maria da Glória de Morais. Tradução de: The voices of society: literacy, conscientiousness and power. DELTA, São Paulo, v.14, n. 2, p. 331-338. 1998.

MOREIRA, Carla. Letramento digital: do conceito à prática. Anais do SIELP. Uberlândia: EDUFU, v. 2, n. 1. 2012. ISSN 2237-8758.

NEVES, Barbara Coelho. Resenha de WARSCHAUER, Mark. Technology and social inclusion: rethinking the digital divide. Massachusetts: MIT Press, 2003. Ponto de Acesso, Salvador, v.2, n.2, p. 170-174, ago. /set. 2008. Disponível em: < www.pontodeacesso.ici.ufba.br>. Acesso em: 20 nov. 2013.

PORTO, Tania Maria Esperon. As tecnologias de comunicação e informação na escola; relações possíveis... relações construídas. Revista Brasileira de Educação, Rio de Janeiro, v. 11 n. 31 jan./abr. 2006. Disponível em: <http://www.scielo.br/scielo.php?pid=S1413-

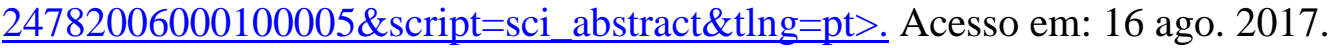

PRENSKY, Marc. Nativos Digitais Imigrantes Digitais. On the Horizon. New York, NCB University Press, v. 9, n. 5, Oct. 2001. Disponível em:

$<$ http://www.colegiongeracao.com.br/novageracao/2_intencoes/nativos.pdf $>$. Acesso em: 7 nov. 2017.

RIBEIRO, Ana Elisa F. Ler na tela: novos suportes para velhas tecnologias. 2003. $112 \mathrm{f}$. Dissertação (Mestrado em Estudos Linguísticos, Inter-relações entre linguagem, cultura e cognição). Faculdade de Letras, Universidade Federal de Minas Gerais, Belo Horizonte, 2003. Disponível em: $<$ http://www.leffa.pro.br/tela4/Textos/Textos/Teses/ana\%20elisa.pdf $>$. Acesso em 20 de jun. 2017.

RIBEIRO, Ana Elisa F. Navegar lendo, ler navegando. Notas sobre a leitura de jornais impressos e digitais. Belo Horizonte: InterDitado, 2009. (Coleção Indie). 
ROBREDO, Jaime. Considerações prospectivas para as próximas décadas sobre a evolução da informação no Brasil: o perfil dos novos profissionais da informação. Revista Brasileira de Biblioteconomia e Documentação, São Paulo, v.22, n.3/4, p.13-31, jul./dez. 1989.

ROCHA, Carolini da et al. Abordagens das revistas brasileiras de Ciência da Informação e Biblioteconomia a respeito do letramento informacional. Revista ACB: Biblioteconomia em Santa Catarina, Florianópolis, v. 13 n. 1 p. 145 158, jan/jun, 2008. Disponível em: < http://www.brapci.inf.br/_repositorio/2010/07/pdf_1647527d10_0011267.pdf $>$. Acesso em 8 jan. 2018.

SOARES, Magda. Novas práticas de leitura e escrita: letramento na cibercultura. Educação e Sociedade, Campinas, vol.23, n.81, p.143-160, dez. 2002. Disponível em: < http://www.scielo.br/scielo.php?pid=s0101-

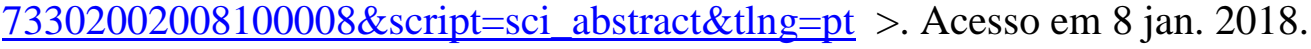

SOARES, Magda. Letramento: um tema em três gêneros. 2.ed. Belo Horizonte: Autêntica, 2006, 128p.

SCHWARTZ, Ann C., McDONALD, William M., VAHABZADEH Arshya B., COTES, Robert O. Keeping up with changing times in education: fostering lifelong learning of millennial learners. Focus, Washington, DC, v.16, issue 1, Winter p. 74-79, 2018. Disponível em: 〈https://focus.psychiatryonline.org/doi/full/10.1176/appi.focus.20170004 >. Acesso em: 2 mar 2018.

SIQUEIRA, Ethevaldo. Como viveremos: o futuro, na visão de 50 famosos cientistas e futurologistas do Brasil e do mundo. São Paulo: Saraiva, 2004.

SOUZA, Valeska Virgínia Soares. Letramento digital e formação de professores. Revista Língua Escrita, n. 2, p. 55-69, dez. 2007. Disponível em:

$<$ http://www.ceale.fae.ufmg.br/app/webroot/files/uploads/revista\%20lingua\%20escrita/Lingu aEscrita_2.pdf >. Acesso em 6 mar 2017.

TAPSCOTT, Don. Geração Digital. São Paulo, São Paulo: Macron Books, 1999.

XAVIER, Antonio Carlos dos Santos. Letramento digital e ensino. Online. 9p. Disponível em:

< http://www.ufpe.br/nehte/artigos/Letramento\%20digital\%20e\%20ensino.pdf $>$. Acesso em: 25 nov. 2013.
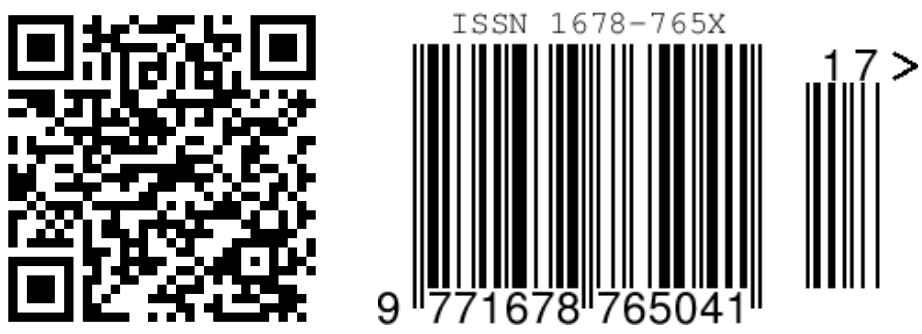

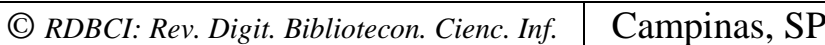

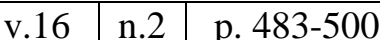

maio/ago. 2018 